\title{
Predictive Value of Skin Color for Illness Severity in the High-Risk Newborn
}

\author{
CLAUDIO DE FELICE, MARIA LAURA FLORI, MICHELE PELLEGRINO, PAOLO TOTI, \\ ELISABETTA STANGHELLINI, ANTONIETTA MOLINU, PIERO TOSI, AND FRANCO BAGNOLI \\ Department of Pediatrics, Obstetrics and Reproduction [C.D.F., F.B.]; Institute of Dermatology [M.L.F., \\ M.P., E.S., A.M.]; and Institute of Pathology [P. Toti, P. Tosi]; University of Siena, I-53100 Siena, Italy.
}

\begin{abstract}
The relationship between skin color and illness severity in the newborn remains untested. We have evaluated the predictive value of skin color readings for illness severity in a population of high-risk newborn infants. A prospective study was conducted on 107 white newborns in the intensive care unit, which were categorized as either high or low severity of illness, defined by the presence of severe neonatal morbidity. Illness severity was also determined using a Score for Neonatal Acute Physiology (SNAP). Color readings were obtained at 10 different body sites using a portable tristimulus colorimeter during the first $24 \mathrm{~h}$, and color was expressed using the standard CIE L*a*b* system. Skin $\mathrm{CIE} \mathrm{b}^{*}$ values were significantly lower in the high severity group $(p<0.0001)$, and a significant inverse correlation with SNAP was observed ( $r_{s}$ range, -0.37 to $\left.-0.71, p<0.0001\right)$. In
\end{abstract}

\section{ABSTRACT}

particular a low $b^{*}$ value for the abdomen was found to be a significant predictor of illness severity ( $92.6 \%$ sensitivity; $96.6 \%$ specificity; $96 \%$ positive predictive value; $93.7 \%$ negative predictive value; adjusted odds ratio, 14.7 ; $95 \%$ confidence interval, 6.4 to 33.8). Our findings indicate that skin color reflects clinical severity in the newborn and that skin colorimetry can accurately identify higher risk infants. (Pediatr Res 51: 100-105, 2002)

Abbreviations
SNAP, Score for Neonatal Acute Physiology
CIE, Commission Internationale de L'Eclairage
NICU, Neonatal Intensive Care Unit
ROC, Receiver-Operating Characteristic

Skin color is considered to be an essential aspect in the physical examination of the newborn (1). However, its evaluation is neither accurate nor reproducible, being subject to individual interpretation and several variables other than pathology. Color is also a complex concept to describe and communicate. Besides jaundice (2), subjective skin color changes are known to be associated with several physiopathologic conditions of the newborn, including hypoxia (3), infection (4), anemia (5), and stress response (6).

In common practice it has long been believed that skin color in the neonate can indicate the degree of severity of illness, although this hypothesis has not been rigorously tested. Nowadays, instruments are available that are easy to use, portable, of relatively low cost, and able to accurately measure color. In the present study we have analyzed the hypothesis that objective skin color evaluation in the first day of admission can be used to predict illness severity in high-risk newborn infants.

Received February 9, 2001; accepted July 16, 2001.

Correspondence and reprint requests: Claudio De Felice, M.D., U.O. Terapia Intensiva Neonatale, Dipartimento di Pediatria, Ostetricia e Medicina della Riproduzione, Azienda Ospedaliera Senese Policlinico, Viale M. Bracci 16, I-53100 Siena, Italy; e-mail: defelice.claudio@libero.it

Supported in part by a grant from the Italian Ministry of Education MURST (funding for research of National Interest).

\section{METHODS}

Subjects. The study was conducted in a level III NICU and was approved by the Institutional Review Board, with informed consent of the parents. One hundred seven randomly selected (random algorithm; Minitab release 9.2 statistical software package; Minitab, Inc., State College, PA, U.S.A.), newborn white infants (47 males, 60 females) admitted to the NICU were enrolled. Exclusion criteria were known skin disease; infants born to mothers with chronic severe anemia or intrapartum hemorrhage; gestational diabetes or other endocrine disorders; illicit drug abuse; maternal intrapartum fever; or fetal hemolysis. Cases of discharge or death at $<24 \mathrm{~h}$ after admission to the NICU were also excluded. To evaluate the possible risk of infection related to the use of an instrument to be shared among different neonates, the rate of nosocomial infections was recorded and compared with that of a similar period in the same NICU. Nosocomial infections were defined according to the National Nosocomial Infections Surveillance System (7). Biologic data, demographic information, and clinical outcomes, independently obtained by two neonatologists who were unaware of the results of the color recordings, were prospectively recorded.

Evaluation of illness severity. The newborns were categorized as either high or low severity of illness, defined by death 
at age $<28 \mathrm{~d}$ or severe neonatal morbidity, as determined by the presence of at least one of the following: sepsis or pneumonia; bronchopulmonary dysplasia; intraventricular hemorrhage $\geq 3$; periventricular leukomalacia $\geq 2$; retinopathy of prematurity $\geq 3$; and necrotizing enterocolitis. Sepsis and pneumonia were defined as described (8). Bronchopulmonary dysplasia was defined by the need for supplemental oxygen after the first $28 \mathrm{~d}$ of life, in association with respiratory signs and typical radiographic findings (9). Necrotizing enterocolitis (10) and retinopathy of prematurity (11) (grades 1-5) were determined according to internationally recognized criteria. Infants were assessed for intraventricular hemorrhage (grades 1-4) and periventricular leukomalacia (grades 1-3), which were classified according to standard systems (12).

In addition to the clinical assessment, illness severity at $24 \mathrm{~h}$ was evaluated using the SNAP, which records deviations from the normal range of 34 routinely available vital signs and laboratory test results (13). Therapeutic intensity was also calculated as described (14).

Quantitative color measurements. Skin color was measured with a Chroma Meter CR-300 (Minolta, Osaka, Japan), a portable tristimulus colorimeter with a standard $\mathrm{D}_{65}$ illuminant (correlated color temperature of $6504 \mathrm{~K}$ ) and $2^{\circ}$ angle supplementary standard observer, after calibration against standard white before each series of measurements (mean percentage of deviation from calibration standard, $\mathrm{L}^{*}, \pm 1.23 \%$; $\mathrm{a}^{*}, \pm 0.29 \%$; and $\mathrm{b}^{*}, \pm 0.29 \%$ points). Colorimetry measures colors with quantitative physical methods and can define them within well-established numerical values (15). Here they are expressed using the standard CIE $\mathrm{L}^{*} \mathrm{a}^{*} \mathrm{~b}^{*}$ system (16). L*, a*, and $\mathrm{b}^{*}$ values (nondimensional units) refer to the three axes of the system: a lightness axis (white-black; $\mathrm{L}^{*}$ ); and two axes representing both hue and chroma, one red-green $\left(a^{*}\right)$ and the other blue-yellow $\left(b^{*}\right)$. This system provides an unambiguous description of color and has the advantage that color differences between samples can be determined using simple computer programs (15). To minimize bias caused by intra- or interobserver variability, readings were performed independently by two experienced dermatologists, unaware of the clinical findings, each of whom made two readings at 10 body sites on one arbitrarily chosen side of the body (forehead, cheek, forearm, palm, upper chest, abdomen, back, buttock, leg, and sole), at three different times: time 0 (admission to the NICU) and +12 and $+24 \mathrm{~h}$. Readings were not taken either during the first $10 \mathrm{~min}$ after birth or during apnea or seizures, to exclude the effects of immediate early postnatal adaptation on the infants' skin color (3). Vernix caseosa was carefully removed. In cases in which phototherapy was being used, an interval of at least $30 \mathrm{~min}$ was used before performing the color measurements. Color readings were not taken in skin areas with common benign ephemeral cutaneous lesions and were taken (as well as skin temperature at each site) while the infants were either awake (not crying) or asleep. Environmental light, temperature, and relative humidity conditions were maintained constant inside the NICU and open radiant warmer beds or thermoregulated incubators.

The colorimeter probe was disinfected with a chlorhexidine 1:10,000 solution each time. To account for possible influences of inheritable characteristics on the infant skin color, the CIE $\mathrm{L} * \mathrm{a} * \mathrm{~b} *$ values were obtained for the parents' constitutional skin (buttock).

Data analysis. Data are expressed as mean \pm SD for continuous normally distributed data and medians with interquartile range (25th and 75th percentiles) for nonnormal distributions. The $t$ test, Mann-Whitney $U$ test, and $\chi^{2}$ test or Fisher's exact test were used to compare continuous normally distributed data, nonparametric continuous data, and categorical data, respectively. Correlation analysis between the CIE $\mathrm{L}^{*} \mathrm{a} * \mathrm{~b} *$ values and SNAP scores was performed with the use of Spearman's rho $\left(r_{s}\right)$, as variables were not normally distributed. Predictive accuracy for identifying newborns with severe neonatal morbidity or adverse outcome for different cutoff values of $\mathrm{L}^{*} \mathrm{a} \mathrm{b}^{*}$ at different anatomic sites, was calculated using ROC curve analysis (17). The predictive accuracy of color readings was compared with that of SNAP. Model calibration was evaluated using $\chi^{2}$ to compare the observed values (according to the classification of the infants into the two illness severity groups) with the expected values (according to the CIE $L * a * b *$ values). The effects of potential confounders on the relationship between colorimetric variables from different body sites and the study end point (illness severity) were examined using multivariable logistic regression, and factors with $p$ values of $<0.25$ at univariate analysis were included in the models (18). Statistica software (StatSoft, Tulsa, OK, U.S.A.), SPSS release 6.1 statistical package (SPSS Inc., Chicago, IL, U.S.A.), and MedCalc software (MedCalc Software, Mariakerke, Belgium) were used. A two-sided $p$ value of $<0.05$ was considered to be statistically significant, and the Bonferroni corrected significance levels were used for multiple $t$ tests.

\section{RESULTS}

Study population characteristics. The demographic and clinical characteristics of the infants examined are shown in Table 1. Median postnatal age on admission to the NICU was $0.10 \mathrm{~h}$ (interquartile range, $0.06-0.25 \mathrm{~h}$ ). SNAP scores ranged from 0 to 42. During the examination period, there was no significant increase in the rate of nosocomial infections, which could have been attributed to the introduction of an additional instrument (3.6 versus 4.7 infections/1000 patient-d, $p=1.0$ ).

Table 1. Demographic and clinical characteristics of the neonatal study group

\begin{tabular}{lc}
\hline \multicolumn{1}{c}{ Variable } & Values \\
\hline Male:Female & $47: 60$ \\
Gestational age (wk) & $35.1 \pm 4.0^{*}$ \\
Birth weight (g) & $2380 \pm 960^{*}$ \\
Vaginal delivery, $n(\%)$ & $41(38.3)$ \\
Sepsis, $n(\%)$ & $10(9.3)$ \\
Pneumonia, $n(\%)$ & $5(4.7)$ \\
Bronchopulmonary dysplasia, $n(\%)$ & $10(9.3)$ \\
Intraventricular hemorrhage, $n(\%)$ & $22(20.6)$ \\
Periventricular leukomalacia, $n(\%)$ & $8(7.5)$ \\
Retinopathy of prematurity, $n(\%)$ & $2(1.9)$ \\
Necrotizing enterocolitis, $n(\%)$ & $1(0.9)$ \\
Death, $n(\%)$ & $2(1.9)$ \\
\hline
\end{tabular}

\footnotetext{
$*$ Values are mean $\pm \mathrm{SD}$.
} 
According to the predefined criteria, 50 neonates $(46.7 \% ; 21$ males, 29 females) were allocated to the high severity group and 57 (26 males, 31 females) to the low severity group (Table 2). Male to female ratio, gestational age, and birth weight were not different between the two severity groups. There was a significant difference between the arterial blood $\mathrm{pH}$, arterial $\mathrm{Po}_{2}$, and the $\mathrm{PO}_{2}$ to fraction inspired oxygen ratio values between the groups, which were lower in the high severity group, and SNAP scores, which were higher $(p<0.0001)$. No significant differences between concentrations of $\mathrm{Hb}$ and total bilirubin peak values were observed $(p \geq 0.11)$. In the high severity group there were a greater number of infants requiring endotracheal intubation, assisted ventilation, oxygen supplementation, exogenous surfactant administration, use of vasopressor agents, and prolonged stay in the NICU (data not shown, $p \leq 0.01)$. No significant differences in the CIE L*a*b* values for the parents' constitutional skin were observed between the two groups (data not shown, $p \geq 0.68$ ).

Colorimetry and illness severity. The total number of readings per observer was 3210 (107 infants $\times 3 \times 10$ sites), and median time needed for each was $9.2 \mathrm{~s}$ (interquartile range, 8.8-9.4 s; $n=50$ ). Intra- and interobserver coefficients of variations were between $3.5 \%\left(\mathrm{~L}^{*}, 2.0 \%\right.$; $\mathrm{a}^{*}, 3.5 \%$; $\left.\mathrm{b}^{*}, 1.0 \%\right)$ and $8 \%\left(L^{*}, 3.5 \% ; a^{*}, 8.0 \% ; b^{*}, 2.5 \%\right)$, respectively. The median skin temperature of the examined sites was $35^{\circ} \mathrm{C}$ (interquartile range, $34-35.5^{\circ} \mathrm{C}$ ).

In Table 3, the $\mathrm{L}^{*} \mathrm{a}^{*} \mathrm{~b}^{*}$ values for each measurement site are shown (only the values for time 0 are included, as those for the successive time measurements were not significantly different; $p \geq 0.9$ ). Median $\mathrm{L}^{*}$ values ranged from 53.58 (palm) to 60.48 (cheek), a* ranged from 13.67 (abdomen) to 20.09 (sole), and $b^{*}$ ranged from 10.71 (sole) to 18.96 (cheek). CIE $b^{*}$ values were significantly different between the two severity groups ( $p$ $<0.0001)$ (Table 4). This applied to all the sites. However, for the $\mathrm{L}^{*}$ and $\mathrm{a}^{*}$ values, significant differences were observed at

Table 2. Comparison of relevant clinical characteristics of two illness severity categories of newborns $\mathbb{}$

\begin{tabular}{|c|c|c|c|}
\hline \multirow[b]{2}{*}{ Variables } & \multicolumn{2}{|c|}{ Illness severity } & \multirow[b]{2}{*}{$p$ value* } \\
\hline & High & Low & \\
\hline Male:Female & $21: 29$ & $26: 31$ & 0.84 \\
\hline Gestational age (wk) & $35.0 \pm 3.8$ & $35.2 \pm 4.0$ & 0.79 \\
\hline Birth weight (g) & $2370 \pm 970$ & $2390 \pm 940$ & 0.91 \\
\hline Vaginal delivery, $n(\%)$ & $17(34)$ & $24(42)$ & 0.43 \\
\hline Blood $\mathrm{pH}$, arterial & $7.268 \pm 0.07$ & $7.332 \pm 0.08$ & $<0.0001$ \\
\hline $\mathrm{Po}_{2}$, arterial $(\mathrm{kPa})$ & $5.54 \pm 2.15$ & $8.03 \pm 2.57$ & $<0.0001$ \\
\hline $\mathrm{PCO}_{2}$, arterial $(\mathrm{kPa})$ & $6.91 \pm 1.68$ & $5.7 \pm 1.12$ & $<0.0001$ \\
\hline $\mathrm{Po}_{2} / \mathrm{FiO}_{2}$ ratio $\dagger$ & $1.16 \pm 0.76$ & $2.94 \pm 1.05$ & $<0.0001$ \\
\hline Oxygenation index $\dagger$ & $1.29 \pm 0.31$ & $0.28 \pm 0.13$ & $<0.0001$ \\
\hline Hemoglobin (mM) & $2.6 \pm 0.25$ & $2.71 \pm 0.42$ & 0.11 \\
\hline Total bilirubin peak $(\mu \mathrm{M})$ & $123.12 \pm 61.56$ & $106.02 \pm 51.3$ & 0.12 \\
\hline SNAP & $19(17-34)$ & $5(1-10)$ & $<0.0001$ \\
\hline NTISS§ & $21(17-24)$ & $10(7-13)$ & $<0.0001$ \\
\hline Length of stay (d) & $21(12-36)$ & $6 \quad(2-8)$ & $<0.0001$ \\
\hline
\end{tabular}

* Bonferroni corrected levels.

$\dagger$ Newborns requiring oxygen supplementation.

$\ddagger$ Score for Neonatal Acute Physiology.

$\S$ Neonatal Therapeutic Intervention Scoring System.

ๆ Plus-minus values are mean $\pm \mathrm{SD}$; nonnormally distributed continuous variables are expressed as medians (25th-75th percentiles).
Table 3. Skin colorimetry results, expressed as CIE $L^{*} a * b *$ values, in the entire population of infants examined

\begin{tabular}{lcll}
\hline \multicolumn{1}{c}{ Site } & \multicolumn{1}{c}{$\mathrm{L}^{*}$} & $\mathrm{a}^{*}$ & \multicolumn{1}{c}{$\mathrm{b}^{*}$} \\
\hline Forehead & $55.19(51.68,57.96)$ & $14.33(12.54,16.39)$ & $15.86(10.24,18.64)$ \\
Cheek & $60.48(57.23,63.22)$ & $18.10(15.11,20.60)$ & $18.96(12.77,22.24)$ \\
Chest & $60.10(56.97,63.80)$ & $14.47(12.12,17.07)$ & $15.83(10.26,20.04)$ \\
Forearm & $58.90(56.31,62.53)$ & $15.22(12.94,17.34)$ & $15.58(10.20,18.49)$ \\
Palm & $53.58(49.63,56.92)$ & $18.26(15.54,20.90)$ & $11.75(8.40,14.01)$ \\
Abdomen & $57.60(54.84,60.85)$ & $13.67(12.07,15.64)$ & $13.91(9.0,16.55)$ \\
Back & $58.59(56.79,60.60)$ & $15.06(12.58,17.48)$ & $15.21(11.50,18.40)$ \\
Buttock & $57.58(54.25,59.95)$ & $18.46(16.32,21.63)$ & $16.11(11.35,18.25)$ \\
Leg & $59.82(55.98,64.54)$ & $15.39(12.25,18.43)$ & $14.97(10.36,17.87)$ \\
Sole & $54.69(50.98,58.23)$ & $20.09(17.11,22.34)$ & $10.71(8.19,13.41)$ \\
\hline
\end{tabular}

Values are medians (25th-75th percentiles; nondimensional units).

Table 4. Comparison of skin colorimetric analyses of two illness severity categories of newborns at time 0

\begin{tabular}{|c|c|c|c|}
\hline \multirow[b]{2}{*}{ Variable } & \multicolumn{2}{|c|}{ Illness severity } & \multirow[b]{2}{*}{$p$ value } \\
\hline & High & Low & \\
\hline \multicolumn{4}{|l|}{ Forehead } \\
\hline $\mathrm{L}^{*}$ & $55.62(53.05,58.94)$ & $54.39(50.82,57.44)$ & 0.75 \\
\hline$a^{*}$ & $13.76(12.23,15.70)$ & $14.76(12.91,16.75)$ & 0.79 \\
\hline$b^{*}$ & $10.03(8.80,12.44)$ & $17.88(16.02,19.96)$ & $<0.00001$ \\
\hline \multicolumn{4}{|l|}{ Cheek } \\
\hline $\mathrm{L}^{*}$ & $61.69(58.89,65.78)$ & $59.92(56.75,61.98)$ & 0.96 \\
\hline$a^{*}$ & $16.61(13.24,19.46)$ & $18.74(15.99,21.13)$ & 0.80 \\
\hline$b^{*}$ & $12.05(10.71,15.03)$ & $21.02(18.92,23.59)$ & $<0.00001$ \\
\hline \multicolumn{4}{|l|}{ Chest } \\
\hline $\mathrm{L}^{*}$ & $60.43(56.40,65.32)$ & $60.00(57.09,63.24)$ & 0.42 \\
\hline$a *$ & $13.74(10.87,16.51)$ & $14.79(12.63,17.49)$ & 0.81 \\
\hline$b^{*}$ & $9.36(8.18,11.68)$ & $18.90(16.0,21.91)$ & $<0.0000 .1$ \\
\hline \multicolumn{4}{|l|}{ Forearm } \\
\hline $\mathrm{L}^{*}$ & $58.83(57.07,62.66)$ & $58.98(56.11,62.44)$ & 0.39 \\
\hline$a^{*}$ & $13.99(12.29,16.65)$ & $16.01(13.62,18.41)$ & 0.037 \\
\hline $\mathrm{b}^{*}$ & $10.07(8.65,13.44)$ & $18.22(16.76,20.19)$ & $<0.00001$ \\
\hline \multicolumn{4}{|l|}{ Palm } \\
\hline $\mathrm{L}^{*}$ & $53.64(49.80,58.01)$ & $53.38(49.49,56.74)$ & 0.24 \\
\hline$a^{*}$ & $17.31(15.01,20.38)$ & $18.89(16.24,21.24)$ & 0.577 \\
\hline$b^{*}$ & $8.14(6.44,10.05)$ & $13.11(11.75,15.59)$ & $<0.00001$ \\
\hline \multicolumn{4}{|l|}{ Abdomen } \\
\hline $\mathrm{L}^{*}$ & $58.10(55.81,61.37)$ & $56.94(54.04,59.53)$ & 0.0038 \\
\hline$a *$ & $13.57(11.31,15.21)$ & $13.89(12.50,17.10)$ & 0.87 \\
\hline$b^{*}$ & $7.47(6.11,9.70)$ & $15.97(13.91,17.56)$ & $<0.00001$ \\
\hline \multicolumn{4}{|l|}{ Back } \\
\hline $\mathrm{L}^{*}$ & $59.39(57.56,61.02)$ & $57.58(56.22,60.10)$ & 0.057 \\
\hline$a^{*}$ & $14.12(12.22,15.13)$ & $16.41(14.42,20.12)$ & $<0.00001$ \\
\hline$b^{*}$ & $10.15(9.55,13.63)$ & $18.16(15.73,20.30)$ & $<0.00001$ \\
\hline \multicolumn{4}{|l|}{ Buttock } \\
\hline $\mathrm{L}^{*}$ & $57.96(55.53,61.61)$ & $56.92(54.07,59.00)$ & 0.2615 \\
\hline$a^{*}$ & $16.57(14.88,18.25)$ & $20.15(17.68,22.02)$ & 0.0001 \\
\hline$b^{*}$ & $10.60(8.57,12.35)$ & $17.99(16.19,18.80)$ & $<0.00001$ \\
\hline \multicolumn{4}{|l|}{ Leg } \\
\hline $\mathrm{L}^{*}$ & $59.69(56.28,67.49)$ & $59.83(55.78,63.82)$ & 0.49 \\
\hline$a^{*}$ & $14.28(11.21,17.38)$ & $20.15(17.68,22.02)$ & 0.53 \\
\hline$b^{*}$ & $9.86(8.13,12.32)$ & $17.13(14.97,19.06)$ & $<0.0001$ \\
\hline \multicolumn{4}{|l|}{ Sole } \\
\hline $\mathrm{L}^{*}$ & $54.45(51.04,58.51)$ & $54.88(50.96,57.95)$ & 0.79 \\
\hline$a^{*}$ & $19.01(15.84,21.76)$ & $20.81(17.89,22.77)$ & 0.11 \\
\hline$b^{*}$ & $8.00(6.54,9.07)$ & $12.87(10.68,14.17)$ & $<0.0001$ \\
\hline
\end{tabular}

fewer sites. Moreover, a significant inverse correlation between the $\mathrm{b}^{*}$ values at each site and SNAP was found: $r_{s}$ values ranging from -0.37 (sole) to -0.71 (back) (all $p$ values $<0.0001$; Table 5). To a lesser degree, the $\mathrm{a}^{*}$ component is 
Table 5. Spearman rank correlations between skin colorimetry at time 0 and SNAP values

\begin{tabular}{|c|c|c|}
\hline Variable & $r_{s}(95 \% \mathrm{CI})$ & $p$ value \\
\hline \multicolumn{3}{|l|}{ Forehead } \\
\hline $\mathrm{L}^{*}$ & $0.04(-0.07,0.15)$ & 0.43 \\
\hline$a^{*}$ & $-0.27(-0.37,-0.17)$ & $<0.0001$ \\
\hline $\mathrm{b}^{*}$ & $-0.52(-0.60,-0.44)$ & $<0.0001$ \\
\hline \multicolumn{3}{|l|}{ Cheek } \\
\hline $\mathrm{L}^{*}$ & $0.22(0.04,0.39)$ & 0.017 \\
\hline$a^{*}$ & $-0.36(-0.51,-0.20)$ & $<0.0001$ \\
\hline $\mathrm{b}^{*}$ & $-0.41(-0.48,-0.33)$ & $<0.0001$ \\
\hline \multicolumn{3}{|l|}{ Chest } \\
\hline $\mathrm{L}^{*}$ & $-0.32(-0.47,-0.14)$ & 0.001 \\
\hline$a^{*}$ & $-0.25(-0.41,-0.08)$ & 0.0005 \\
\hline $\mathrm{b}^{*}$ & $-0.45(-0.58,-0.30)$ & $<0.0001$ \\
\hline \multicolumn{3}{|l|}{ Forearm } \\
\hline $\mathrm{L}^{*}$ & $-0.07(-0.29,0.16)$ & 0.55 \\
\hline$a^{*}$ & $-0.14(-0.35,-0.08)$ & 0.081 \\
\hline $\mathrm{b}^{*}$ & $-0.56(-0.68,-0.41)$ & $<0.0001$ \\
\hline \multicolumn{3}{|l|}{ Palm } \\
\hline $\mathrm{L}^{*}$ & $-0.16(-0.34,0.02)$ & 0.077 \\
\hline$a^{*}$ & $-0.04(-0.21,0.14)$ & 0.68 \\
\hline $\mathrm{b}^{*}$ & $-0.40(-0.48,-0.31)$ & $<0.0001$ \\
\hline \multicolumn{3}{|l|}{ Abdomen } \\
\hline $\mathrm{L}^{*}$ & $0.21(-0.06,0.46)$ & 0.13 \\
\hline$a^{*}$ & $-0.29(-0.51,-0.02)$ & 0.032 \\
\hline $\mathrm{b}^{*}$ & $-0.69(-0.78,-0.57)$ & $<0.0001$ \\
\hline \multicolumn{3}{|l|}{ Back } \\
\hline $\mathrm{L}^{*}$ & $0.13(-0.27,0.50)$ & 0.50 \\
\hline$a^{*}$ & $-0.38(-0.60,-0.12)$ & 0.006 \\
\hline$b^{*}$ & $-0.71(-0.85,-0.46)$ & $<0.0001$ \\
\hline \multicolumn{3}{|l|}{ Buttock } \\
\hline $\mathrm{L}^{*}$ & $0.04(-0.18,0.25)$ & 0.72 \\
\hline$a^{*}$ & $-0.43(-0.59,-0.24)$ & $<0.0001$ \\
\hline $\mathrm{b}^{*}$ & $-0.59(-0.69,-0.48)$ & $<0.0001$ \\
\hline \multicolumn{3}{|l|}{ Leg } \\
\hline $\mathrm{L}^{*}$ & $-0.25(-0.41,-0.07)$ & 0.006 \\
\hline$a^{*}$ & $-0.30(-0.45,-0.13)$ & 0.001 \\
\hline$b^{*}$ & $-0.47(-0.54,-0.40)$ & $<0.0001$ \\
\hline \multicolumn{3}{|l|}{ Sole } \\
\hline $\mathrm{L}^{*}$ & $-0.15(-0.32,0.02)$ & 0.085 \\
\hline$a^{*}$ & $-0.16(-0.26,-0.07)$ & 0.001 \\
\hline $\mathrm{b}^{*}$ & $-0.37(-0.45,-0.28)$ & $<0.0001$ \\
\hline
\end{tabular}

also inversely correlated with the SNAP score, $r_{s}$ ranging from -0.04 (palm) to -0.43 (buttock), whereas the $L^{*}$ values were unrelated to SNAP, with the exception of the chest and leg recording sites. There was no significant correlation between the $\mathrm{L} * \mathrm{a} * \mathrm{~b} *$ values and skin temperature, gestational age, birth weight, mode of delivery, Apgar score, sex, and skin colorimetry values of the parents $\left(r_{s}\right.$ [absolute value] $\leq 0.08 ; p \geq$ 0.70 ).

The results of the analysis of predictive accuracy of a low $b^{*}$ value are shown in Table 6: all average area-under-the-curve values were significantly different from 0.5 , ranging from 0.917 (sole) to 0.994 (back). The most sensitive individual site was found to be the forearm (96.3\%), whereas the back showed the highest specificity (96.9\%). The results of an ROC curve comparison analysis indicated that values from the abdomen, back, chest, and leg were not significantly different from SNAP $(p>0.25)$. Overall, the abdomen $\mathrm{b}^{*}$ value showed the highest predictive accuracy (abdomen, positive predictive value $95.98 \%$, negative predictive value $93.7 \%$; back, positive pre- dictive value $92.57 \%$, negative predictive value $98.24 \%$ ), with adequate model calibration $\left(\chi^{2}=0.02, d f=1, p=0.89\right)$. After controlling for potential confounders, a low $b^{*}$ value for the abdomen was found to be significantly associated with illness severity (adjusted odds ratio, 14.7; 95\% confidence interval, 6.4 to 33.8$)$.

\section{DISCUSSION}

A relationship between skin color and illness severity in the newborn is commonly acknowledged but until now has not been validated. The results of the present study indicate that skin color during the first $24 \mathrm{~h}$ from admission reflects illness severity in high-risk newborns and that colorimetry can accurately predict initial clinical severity and adverse outcome.

Colorimetry can provide an unambiguous description of color hue, and the technique is not affected by the factors typically associated with subjective interpretation, such as environmental light source, background contrast, and observerrelated differences. To date, medical applications of colorimetry are limited to the assessment of skin microcirculation (19) and pigmentary changes (20). With the sole exception of transcutaneous bilirubinometry (2), little information is currently available regarding quantitative color data in the newborn (21-24).

Using the CIE $\mathrm{L}^{*} \mathrm{a} \mathrm{b}^{*}$ system, colorimetry describes color using three values: $L^{*}, a^{*}$, and $b^{*}$. Our study indicates that the $\mathrm{b}^{*}$ value has the highest predictive efficiency, whereas $\mathrm{L}^{*}$ and $a^{*}$ appear to be of limited predictive relevance. In particular, a low $\mathrm{b}^{*}$ and, to a lesser extent, low $\mathrm{a}^{*}$ readings (but not $\mathrm{L}^{*}$ ) have been shown to be strongly associated with high 24-h SNAP scores. The observed color changes in the examined newborns were independent of parental constitutional skin color. They were present at each of the anatomic sites tested and at each serial time measurement, which means that these color measurements could be determined using a single site. Although the values at particular anatomic sites can be dependent on each other, of all the sites examined, the values for the abdomen had the greatest predictive efficiency with adequate calibration. Values recorded at time 0 have been shown to be fully informative for the evaluation of the clinical status of the newborn, whereas measurements at successive times did not add further significant information.

Several neonatal severity scoring systems have been developed $(13,25-30)$ for predicting mortality, morbidity, or longterm sequelae and comparing NICU performance (29). The Apgar score (3) is the only commonly used severity scoring method that includes color, but its use is restricted to the immediate postnatal adaptation period and evaluation is subjective and gives limited information. As an independent illness severity predictor, skin colorimetry offers important positive aspects, including 1 ) independence of other outcome predictions, notably gestational age and birth weight; 2) correlation with clinical outcome and a standard severity score (SNAP); 3) absence of invasiveness; 4) possible application at time 0 and immediacy of results; and 5) possible usefulness in different clinical contexts. The importance of noninvasive procedures in neonatology is obvious, as blood sampling for 
Table 6. Predictive accuracy of multiple anatomic site CIE $b^{*}$ and SNAP values in identifying high severity newborn infants: results of ROC curve analyses

\begin{tabular}{|c|c|c|c|c|c|c|c|c|}
\hline Variable & $\begin{array}{c}\text { Area under curve } \pm \text { SEM } \\
(95 \% \mathrm{CI})\end{array}$ & Cutoff value & $\begin{array}{l}\text { Sensitivity, \% } \\
(95 \% \mathrm{CI})\end{array}$ & $\begin{array}{l}\text { Specificity, \% } \\
(95 \% \mathrm{CI})\end{array}$ & $+\mathrm{LR}$ & $-\mathrm{LR}$ & $+\mathrm{PV}$ & $-\mathrm{PV}$ \\
\hline Forehead-b* & $0.915 \pm 0.028(0.847-0.959)$ & $\leq 13.35$ & $75.9(62.4-86.5)$ & $96.6(88.1-99.5)$ & 22.02 & 0.25 & 95.14 & 82.05 \\
\hline Cheek-b* & $0.943 \pm 0.023(0.882-0.978)$ & $\leq 16.12$ & $87.0(75.1-94.6)$ & $91.4(81.0-97.1)$ & 10.10 & 0.14 & 89.87 & 88.91 \\
\hline Forearm-b* & $0.939 \pm 0.023(0.877-0.975)$ & $\leq 16.49$ & $96.3(87.2-99.4)$ & $77.6(64.7-87.5)$ & 4.30 & 0.05 & 79.04 & 95.98 \\
\hline Palm-b* & $0.944 \pm 0.022(0.884-0.979)$ & $\leq 11.09$ & $92.6(82.1-97.9)$ & $86.2(74.6-93.8)$ & 6.71 & 0.09 & 85.47 & 92.99 \\
\hline Abdomen-b* & $0.985 \pm 0.012(0.941-0.998)$ & $\leq 11.43$ & $92.6(82.1-97.9)$ & $96.6(88.1-99.5)$ & 26.85 & 0.08 & 95.98 & 93.70 \\
\hline Leg-b* & $0.967 \pm 0.017(0.914-0.991)$ & $\leq 14.22$ & $94.4(84.6-98.8)$ & $86.2(74.6-93.8)$ & 6.85 & 0.06 & 85.71 & 94.61 \\
\hline Sole-b* & $0.917 \pm 0.027(0.849-0.961)$ & $\leq 10.11$ & $94.4(84.6-98.8)$ & $79.3(66.6-88.8)$ & 4.56 & 0.07 & 79.99 & 94.17 \\
\hline SNAP & $0.974 \pm 0.016(0.925-0.995)$ & $\geq 10$ & $96.3(87.2-99.4)$ & $96.6(88.1-99.5)$ & 27.93 & 0.04 & 96.30 & 96.60 \\
\hline
\end{tabular}

Abbreviations used: $+\mathrm{LR}$, positive likelihood ratio; $-\mathrm{LR}$, negative likelihood ratio; $+\mathrm{PV}$, positive predictive value; $-\mathrm{PV}$, negative predictive value. Plus minus values are means \pm SEM; positive and negative predictive values refer to the observed rate of infants with high severity (46.7\%); cutoff values are expressed as nondimensional units.

diagnostic tests is a major cause of anemia in premature infants (31) and there is increasing awareness concerning possible long-term effects of pain in neonates in intensive care (32). Moreover, colorimetry does not interfere with the usual neonatologic procedures. Our findings also indicate that skin colorimetry is safe and suitable for use in the NICU.

Possible limitations to the present study may be mainly related to the population size examined, but in our statistical scenario differences were highly significant. Besides, the population examined were all white infants, but preliminary observations of high-risk newborns in a multiracial setting indicate that a significant inverse association between $b^{*}$ value and clinical severity persists, as the difference between the skin colorimetry values of those newborns and the currently examined study group appears to reside in the $\mathrm{L}^{*}$ value. In addition, a falsely elevated predictive performance of skin color readings at admission may arise when mortality and morbidity are combined; further research is needed to assess the value of skin colorimetry for identifying the risk of each independent morbidity.

The physicochemical mechanisms underlying the low $b^{*}$ value in severely ill neonates remain unclear. Peripheral desaturation of $\mathrm{Hb}$ and poor perfusion may be partly responsible for these changes, because $\mathrm{Hb}$ saturation and concentration modulate the apparent skin color response mainly in the blue region of the visible spectrum, a wavelength range that significantly contributes to the $b^{*}$ component of the CIE $\mathrm{L}^{*} \mathrm{a} * \mathrm{~b}^{*}$ color space (33).

In conclusion, skin color remains a rather undervalued measurement for diagnostic, prognostic, and therapeutic purposes for the newborn infant. Nevertheless, our findings suggest that skin colorimetry is an objective, noninvasive, quick and easy-to-operate, reproducible, low-cost, and accurate means of predicting clinical severity in the high-risk newborn.

Acknowledgments. The authors thank Katie Henry (editorial assistance); Laura Bianciardi (online research); Alessandra Lombardi and Chiara Ginanneschi (data collection); Dr. Gordon B. Avery, Dr. Maurizio Costantini, and Dr. Giuseppe
Latini (critical reading of the manuscript), Dr. Eduardo Bancalari (helpful discussion), and Prof. Enzo Ballatori and Dr. Luigi Ferrante (statistical advice), as well as the medical and nursing staff of the Neonatal Intensive Care Unit, Azienda Ospedaliera Senese, for their kind collaboration during the course of this study.

\section{REFERENCES}

1. Wiswell TE 1996 Examination of the critically ill neonate. In: Spitzer AR (ed) Intensive Care of the Fetus and Neonate. CV Mosby, St. Louis, pp 337-344

2. Rubaltelli FF, Gourley GR, Loskamp N, Modi N, Roth-Kleiner M, Sender A, Vert P 2001 Transcutaneous bilirubin measurement: a multicenter evaluation of a new device. Pediatrics 107:1264-1271

3. Apgar V 1953 Proposal for a new method of evaluation of the newborn infant. Anesth Analg 32:260-267

4. Spector SA, Ticknor W, Grossman BS 1981 Study of the usefulness of clinical and hematologic findings in the diagnosis of neonatal bacterial infections. Clin Pediatr 20:385-392

5. Ramenofsky ML 1993 Early assessment and management of trauma. In: Ashcraft KW, Holder TM (eds) Pediatric Surgery, 2nd Ed. WB Saunders, Philadelphia, pp $110-121$

6. Van Cleve L, Johnson L, Andrews S, Hawkins S, Newbold J 1995 Pain responses of hospitalized neonates to venipuncture. Neonatal Network 14:31-36

7. Garner JS, Jarvis WR, Emori TG, Horan TC, Hughes JM 1988 CDC definitions for nosocomial infections. Am J Infect Control 16:128-140

8. Moro ML, De Toni A, Stolfi I, Carrieri MP, Braga M, Zunin C 1996 Risk factors for nosocomial sepsis in newborn intensive and intermediate care units. Eur J Pediatr $155: 315-322$

9. Bancalari E, Abdenour GE, Feller R, Gannon J 1979 Bronchopulmonary dysplasia: clinical presentation. J Pediatr 95:819-823

10. Kliegman RM, Fanaroff AA 1984 The necrotizing enterocolitis. N Engl J Med 310:1093-1103

11. [No authors listed] 1984 An international classification of retinopathy of prematurity. The Committee for the Classification of Retinopathy of Prematurity. Arch Ophthalmol 102:1130-1134

12. De Felice C, Toti P, Laurini RN, Stumpo M, Picciolini E, Todros T, Tanganelli P, Buonocore G, Bracci R 2001 Early neonatal brain damage in histologic chorioamnionitis. J Pediatr 138:101-104

13. Richardson DK, Gray JE, McCormick MC, Workman K, Goldmann DA 1993 Score for neonatal acute physiology: a physiologic severity index for neonatal intensive care. Pediatrics 91:617-623

14. Gray JE, Richardson DK, McCormick MC, Workman-Daniels K, Goldmann DA 1992 Neonatal Therapeutic Intervention Scoring System, a therapy-based severityof-illness index. Pediatrics 90:561-567

15. Zollinger H 1999 Colorimetry. In: Zollinger H (ed) Color: A Multidisciplinary Approach. Verlag Helvetica Chimica Acta, Zurich, pp 63-78

16. Robertson AR 1977 The CIE 1976 color-difference formulae. Color Res Appl 2:7-11

17. Zweig MH, Campbell G 1993 Receiver-operating characteristic (ROC) plots: a fundamental evaluation tool in clinical medicine. Clin Chem 39:561-577

18. Hosmer DW, Lemeshow S 1989 Applied Logistic Regression. John Wiley \& Sons, New York

19. Takiwaki H, Overgaard L, Serup J 1994 Comparison of narrow-band reflectance spectrophotometric and tristimulus colorimetric measurements of skin color: twenty- 
three anatomical sites evaluated by the Dermaspectrometer and the Chroma Meter CR-200. Skin Pharmacol 7:217-225

20. Rubegni P, Cevenini G, Flori ML, Fimiani M, Stanghellini E, Molinu A, Barbini P, Andreassi L 1997 Relationship between skin color and sun exposure history: a statistical classification approach. Photochem Photobiol 65:347-351

21. Walsh RJ 1964 Variation in the melanin content of the skin of New Guinea natives at different ages. J Invest Dermatol 42:261-265

22. Ballowitz L, Avery ME 1970 Reflectance of the skin. Studies on infant and adult humans, Wistar and Gunn rats. Biol Neonate 15:348-360

23. Post PW, Krauss AN, Waldman S, Auld PAM 1976 Skin reflectance of newborn infants from 25 to 44 weeks gestational age. Hum Biol 48:541-557

24. Grande R, Gutierrez E, Latorre E, Argueles F 1994 Physiological variations in the pigmentation of newborn infants. Hum Biol 66:495-507

25. Horbar JD, Onstad L, Wright E 1993 Predicting, mortality risk for infants weighing 501 to 1500 grams at birth: a National Institutes of Health Neonatal Research Network report. Crit Care Med 21:12-18

26. [No authors listed] 1995 CRIB (clinical risk index for babies), mortality, and impairment after neonatal intensive care. Scottish Neonatal Consultants' Collaborative Study Group and the International Neonatal Network. Lancet 345:1020-1022
27. Richardson DK, Phibbs CS, Gray JE, McCormick MC, Workman-Daniels K, Goldmann DA 1993 Birth weight and illness severity: independent predictors of neonatal mortality. Pediatrics 91:969-975

28. Karesen PI, Dohlen G, Fundingsrud HP, Dahl LB 1998 The use of CRIB (clinical risk index for babies) score in auditing the performance of one neonatal intensive care unit. Acta Paediatr 87:195-200

29. Bührer C, Grimmer I, Metze B, Obladen M 2000 The CRIB (Clinical Risk Index for Babies) score and neurodevelopmental impairment at one year corrected age in very low birth weight infants. Intensive Care Med 26:325-329

30. Richardson DK, Corcoran JD, Escobar GJ, Kee SK, for the Canadian NICU Network, the Kaiser Permanente Neonatal Minimum Data Set Wide Area Network, and the SNAP-II Study Group 2001 SNAP-II and SNAPPE-II: simplified newborn illness severity and mortality risk scores. J Pediatr 138:92-100

31. Zipursky A 2000 Erythropoietin therapy for premature infants: cost without benefit? Pediatr Res 48:136

32. Ruda MA, Ling Q-D, Hohmann AG, Peng YB, Tachibana T 2000 Altered nociceptive neuronal circuits after neonatal peripheral inflammation. Science 289:628-630

33. Kopola H, Lahti A, Myllylä RA, Hannuksela M 1993 Two-channel fiber optic skin erythema meter. Opt Eng 32:222-226 